\title{
O IMPACTO DA PRIMEIRA GUERRA MUNDIAL SOBRE A EUROPA E A LITERATURA DE GUERRA
}

\begin{abstract}
Volker Jaeckel
Resumo: Hoje, cem anos depois das maiores batalhas navais e de trincheiras, cabe a pergunta: como esta Grande Guerra Europeia mudou não somente as configurações do continente, mas também os conceitos de guerra e de literatura de guerra? Até o século XIX, a guerra era vista por muitos como um ato heroico, pelo qual os homens podiam comprovar a sua valentia numa luta aberta, encarando diretamente o inimigo. Com a nova tecnologia de armas, a morte vem de forma invisível: gás, submarinos, artilharias de longo alcance, minas, aviões, tanques e metralhadoras. Muda-se a estratégia bélica e finda o sentimento de uma luta nobre para defender a pátria. Neste artigo, a grande desilusão com a guerra será exemplificada através dos romances Nada de novo no front (1929) de Erich Maria Remarque, Os quatro cavaleiros do Apocalipse (1916) de Vicente Blasco Ibáñez, abarcando a guerra terrestre, assim como o drama expressionista Batalha naval (1917) de Reinhard Göring.

Palavras-chave: Primeira Guerra Mundial; Guerra das Trincheiras; batalhas navais; Grande Guerra Europeia; literatura de guerra.

Abstract: Nowadays, one hundred years after the greatest sea and trench battles, a question is posed: how could this Great European War change not only the continental configurations, but also the concepts of war and war literature? Until the nineteenth century, many saw war as some heroic act through which men could prove their bravery in an open fight, facing the enemy directly. By means of new weapon technology, death comes invisibly: gas, submarines, long-range artilleries, mines, airplanes, tanks, and machine guns. War strategies are altered and the feeling of a worthy fight in order to defend one's homeland is ended. In this article, the great disillusion with war will be exemplified in the following romances: Erich Maria Remarque's All Quiet in the Western Front (1929); concerning land warfare, Vicente Blasco Ibáñez's The Four Horsemen of the Apocalypse (1916), as well as Reinhard Göring's Expressionist drama Seeschlacht (1917).
\end{abstract}

Keywords: First World War; Trench Warfare; naval warfare; Great European War; war literature. 


\section{INTRODUÇÃO}

No ano de 1916, há exatamente 100 anos, aconteceram as batalhas terrestres e navais mais terríveis que a humanidade conheceu até então, na Grande Guerra Europeia, também chamada de Guerra para acabar com todas as Guerras. Pode-se certamente afirmar que, sem aquelas batalhas e os resultados da guerra, a Europa não teria se transformado no espaço que é hoje. Na batalha de Verdun, que se desenvolveu de 21 de fevereiro a 18 de dezembro de 1916, estima-se que mais de 715.000 soldados tenham perdido suas vidas, sendo tal número de vítimas quase igualmente distribuído entre os exércitos alemão e francês. Esta batalha sangrenta de trincheiras terminou sem conquistas relevantes de terreno e sem um vencedor definido. Em 22 de setembro de 1984, o chanceler alemão Helmut Kohl (cujo pai tinha combatido perto de Verdun, na Primeira Guerra Mundial) e o Presidente francês François Mitterrand (que tinha sido prisioneiro na Segunda Guerra Mundial), reuniramse no cemitério de Douaumont, de mãos dadas, durante alguns minutos, sob a chuva, num gesto de reconciliação franco-alemã.

Nos dias 31 de maio e 01 de junho de 1916 registrou-se a maior batalha naval, a de Jutlândia (ou Skagerrak), na qual se enfrentaram a Hochseeflotte alemã e a Grand Fleet britânica. Participaram, por parte da Inglaterra, 151 navios com 60 mil homens a bordo e, da parte alemã, 99 navios com 45 mil marinheiros. Tal batalha provocou a morte de 6094 soldados britânicos e 2551 soldados alemães. O combate terminou sem um vencedor definido, embora a Alemanha imperial reivindicasse para si a vitória por motivos de propaganda. Foi o início do fim da supremacia britânica nos mares. Os grandes cruzadores de batalha deixaram de dominar as lutas em prol de uma guerra liderada por submarinos e porta-aviões.

Na Primeira Guerra Mundial, jovens de vários países alistaram-se voluntariamente, com muito entusiasmo patriótico, para defender os seus países do inimigo. Era a última das guerras tradicionais, no que concerne à postura dos soldados e, ao mesmo tempo, a primeira guerra moderna no que se refere à tecnologia bélica. Por meio de armas invisíveis, levaram-se imprevisivelmente soldados à morte, já que estes não lutavam mais frente a frente com os inimigos como antigamente.

Esta guerra terrível, que causou a morte de mais de 11 milhões de soldados nos diferentes frentes de combate, - na França, na Itália e na Rússia - mudou completamente as configurações da Europa. O conflito terminou com a derrota das velhas monarquias na Rússia, na Alemanha e na Áustria-Hungria, assim como com a existência desta última como Estado-nação. Pode-se dizer que, a partir deste momento, nasceu a idéia de uma Europa unida e de paz restituída; o desejo por um espaço comum. A guerra com tecnologia moderna comprovou, em muitas ocasiões, que não havia mais vitórias gloriosas e atos de heroísmo. Os ideais de defender uma pátria nobre de um inimigo, um invasor, um vilão, também foram abandonados com a prorrogação da guerra, que se decidiu pelas grandes batalhas de material (Materialschlachten). Depois da guerra surgiu a ideia de uma Sociedade (ou Liga) das Nações, que foi criada com a assinatura do Tratado de Versalhes em junho de 1919.

Mudaram-se as visões da Europa, nas quais o Estado-nação, a amada pátria, tem máxima soberania. Com a Primeira Guerra Mundial, houve ruptura também no que se refere às 
visões da guerra e deu-se início ao desenvolvimento de uma literatura pela primeira vez decididamente antiguerra, categoria na qual se enquadram os três autores apresentados aqui.

A Europa sofreu sérias transformações depois desta guerra, com a perda de territórios da Alemanha e a dissolução da monarquia austro-húngara. Não se deve esquecer que também o conceito da Europa foi alterado com o Tratado de Locarno. A cruel Guerra das Trincheiras foi a base para uma reorganização pacífica da Europa num espaço comum.

\section{ERICH MARIA REMARQUE: NADA DE NOVO NO FRONT}

O representante mais ilustre desta literatura crítica aos atos bélicos é o romancista alemão Erich Maria Remarque, pseudônimo de Erich Paul Remark, nascido no seio de uma família trabalhadora católica alemã. Aos 18 anos partiu para as trincheiras durante a Primeira Guerra Mundial, onde foi ferido várias vezes. Depois da guerra mudou o seu nome para Remarque e teve diversos empregos, incluindo os de bibliotecário, professor e editor.

Em 1929, Remarque publicou a sua obra mais famosa, Im Westen nichts Neues (Nada de novo no front, no Brasil), com o pseudônimo Erich Maria Remarque (seu nome do meio foi alterado em homenagem a sua mãe). Escreveu mais alguns livros de conteúdo semelhante, numa linguagem simples e emotiva, em que descrevia a guerra e o pós-guerra.

Nada de novo no front é um romance antiguerra, no qual os horrores da Primeira Guerra Mundial são narrados a partir do ponto de vista de um jovem soldado, Paul Bäumer. A obra é considerada uma construção perfeita de sequências alternantes entre situações cruéis, aterrorizantes, aberrantes, emocionais e humorísticas, sendo, por fim, o primeiro grande romance anti-guerra. Nada de novo no front foi publicado em forma de folhetim pela Vossische Zeitung em 10 de novembro de 1928 e, em forma de livro, pela Propyläen Verlag no dia 29 de janeiro de 1929. Em 11 semanas foram vendidos mais de 450.000 exemplares e a obra foi traduzida para 26 idiomas ainda no mesmo ano. Atualmente existem edições em 50 línguas, tendo superado, já em 2007, os 20 milhões de exemplares. Não existe outro texto narrativo escrito em alemão mais vendido até hoje. Em 1933, os nazistas baniram e queimaram os livros de Remarque, alegando que o autor nem sequer tinha participado da Primeira Guerra Mundial. Este romance é considerado o mais destacado sobre este episódio histórico.

O próprio Paul é o narrador. A trama começa quando, em algum lugar da Frente Ocidental Europeia, ele e seus companheiros, todos da Segunda Companhia, tentam se recuperar atrás do front, depois que os últimos combates reduziram quase pela metade seu pelotão, de 150 para 80 homens. O rapaz não precisa de muito tempo para mudar bruscamente de opinião. Quando os combates começam, ele se vê cercado de cadáveres de meninos como ele, enquanto outros arrastam-se feridos, mutilados, moribundos. Conclui que trocou sua juventude pela única e cruel certeza, a do absurdo da guerra, independentemente do lado em que está. Em seu relato, descreve como os vinte rapazes da sua turma, patrioticamente, alistaram-se na guerra e tiveram suas vidas, assim como seus valores éticos e morais, destroçados.

O jovem soldado descreve passagens dramáticas de horror aos quais todos são submetidos. Certa noite, e prosseguindo até o dia seguinte, quando o inimigo inicia um bombardeio 
de artilharia, nenhum ataque geral começa, mas ninguém pode deixar o bombardeio para buscar comida. Isto faz com que vários recrutas tenham acessos de insanidade e desespero. O próprio narrador conta que olhou nos olhos de um francês no solo e lançou uma granada de mão nele. Os alemães, em seguida, atingem a linha inimiga e repelem os franceses. Mais baixas entre os soldados se sucedem nos dias seguintes; os homens nem sempre podem recolher seus camaradas feridos na terra-de-ninguém, deixando-os ali para morrer. O bombardeio recomeça com toda força. Novos recrutas são trazidos, mas morrem em quantidades aterrorizantes, por enganos que Paul descreve como tolos, pois são muito inexperientes. Sua companhia chega ao ponto de possuir apenas 32 homens dos 150 iniciais. E mais hão de morrer, pois a guerra está apenas começando para eles.

A obra contrariava o conceito predominante de que a guerra era um mal necessário, uma fatalidade histórica marcada por certo romantismo heroico, que vinha da verdadeira face dos soldados que nela se envolveram. Remarque transformou seus companheiros de batalhas em miseráveis: homens, mulheres e crianças, neuróticos e assustados que, ao mesmo tempo, recorriam à barbaridade para sobreviver. Após uma longa descrição da crueldade e do desrespeito dos oficiais em relação aos recrutas, o narrador observa:

“Tornamo-nos duros, desconfiados, impiedosos, vingativos e brutais - e isso foi bom, porque eram precisamente estas qualidades que nos faltavam. Se nos tivessem mandado para as trincheiras sem este período de formação, a maioria, sem dúvida, teria enlouquecido. Mas, assim, estávamos preparados para o que nos esperava." (REMARQUE, 1974, p. 31)

Nada de Novo no Front pode ser visto como uma fonte importante de informação sobre a Primeira Guerra Mundial. Por outro lado, até então, na literatura mundial, a guerra era retratada como um pano de fundo para romances de aventura. O protagonismo era de bravos heróis, do tipo de Aquiles, que aproveitaram as guerras para ganhar sua fama na literatura; ou, ainda, a guerra era vista com neutralidade, como um mal admissível, como solução para conflitos políticos.

O livro de Erich Maria Remarque pode ser considerado um livro europeu contra a guerra, uma vez que, num encontro com um soldado francês, fica claro que entre os adversários não há pessoas melhores ou piores. Paul Bäumer mata o soldado francês, entretanto, fica com o homem agonizante no mesmo buraco durante muitas horas e estabelece um diálogo interessante com ele, ao longo do qual começa a se preocupar muito com o inimigo, com seus sofrimentos, sua origem e seus parentes.

Neste momento, revela-se toda a arbitrariedade da guerra que se mostra em sua face mais cruel. Segundo Elcio Cornelsen, "é alcançado o ponto alto do romance" (CORNELSEN, 2010 , p. 45), quando Bäumer fere mortalmente com sua faca um soldado francês. Ao contrário do que se espera de um soldado na guerra, ele pretende mostrar que tenta ajudá-lo para dominar seus sentimentos de culpa e compaixão. Quer cuidar dele para mostrar a sua intenção de não matá-lo ou de anular tal intenção, assim como sente a necessidade de mostrar para os adversários, caso seja preso, que desejava ajudá-lo para evitar, assim, o próprio fuzilamento. 
Ele chama o francês de "companheiro" e "camarada" e finalmente constata sua morte às três horas da tarde. Porém, mesmo após o falecimento do adversário, Bäumer presta-lhe cuidados e tenta descobrir sua identidade. De maneira quase obsessiva, não consegue impedir-se de pensar nele.

"Este morto está atrelado à minha vida: Por isso tenho de fazer e prometer tudo, para me salvar: juro cegamente que pretendo viver só para ele e para sua família; com lábios úmidos, dirijo-me a ele... nas profundidades do meu ser reside a esperança de que, com isto, resgatarei o meu ato, e, talvez, ainda consigo escapar; é um pequeno ardil: se, ao menos, me for permitido escapar, então cuidarei disto. Em seguida, abro a caderneta e leio, devagar: Gerárd Duval, tipógrafo.” (REMARQUE, 1974, p.185)

Nesta cena, observa-se uma atitude inusitada para com um soldado em guerra: o protagonista mostra arrependimentos amargos por ter matado o adversário e não consegue se livrar do sentimento de culpa, lutando contra o seu destino quando pensa:

"Com certeza, o morto poderia ter vivido ainda uns trinta anos, se eu tivesse gravado melhor o caminho de volta. Se tivesse corrido dois metros mais para a esquerda, ele estaria agora deitado na trincheira, escrevendo outra carta para a mulher." (REMARQUE, 1974, p.183)

O romance de Remarque desmitifica o heroísmo de guerra em todas as suas aparências e desmascara a estrutura do militarismo prussiano como desumano, covarde e inútil na personagem do sargento Himmelsto $\beta$, que maltrata e humilha os recrutas durante a sua formação, provocando ira e ódio contra ele.

O canhoneio permanente e intensivo que o batalhão de Paul Bäumer sofre, durante dias e noites, desmoraliza a tropa e leva alguns soldados à beira da loucura. O narrador-protagonista deixa o leitor participar desta tragédia de uma forma arrepiante, como se infere em cenas como esta:

"As linhas da retaguarda param. Não conseguem avançar. O ataque é paralisado pela nossa artilharia.

Ficamos à espreita. O fogo salta cem metros à frente - retomamos a ofensiva. Ao meu lado, a cabeça de um cabo é arrancada. Ainda corre mais alguns passos, enquanto o sangue jorra-lhe do pescoço, como um repuxo." (REMARQUE, 1974, p.101) ${ }^{1}$

O grotesco dessa descrição é a aparência surreal de um homem sem cabeça, ainda caminhando. O narrador mostra, também, sua incapacidade momentânea e a dúvida de matar. Ele justifica-se alegando que não lança granadas contra homens, senão contra a própria morte que persegue os soldados em forma humana, quando diz:

1 Compare com a descrição igualmente surreal do homem sem cabeça em BLASCO IBÁÑEZ, 2008, p. 356-367, comentada aqui mais adiante. 
"No momento em que começamos a recuar, três rostos emergem do chão à nossa frente. Embaixo de um dos capacetes, um cavanhaque escuro e dois olhos que me fitam com firmeza. Levanto a mão, porém, não consigo nestes olhos estranhos. Durante um momento de loucura, toda a matança gira como um turbilhão à minha volta e os dois olhos são a única coisa imóvel em todo o quadro; então, a cabeça se mexe, vejo uma mão, um movimento, e logo minha granada de mão voa pelo ar, quase que independente de mim [...]"

Tornamo-nos animais selvagens. Não combatemos, defendemo-nos da destruição. Sabemos que não lançamos as granadas contra homens, senão contra a Morte, que nos persegue com as mãos e capacetes." (REMARQUE, 1974, p.100)

Erich Maria Remarque evidencia ao leitor que a guerra é uma grande insensatez e que os campos de batalha revelaram outra realidade, diferente daquela ensinada na escola com o enaltecimento da pátria (CORNELSEN, 2010, p. 51). A guerra não é mais um lugar para se fazer grandes façanhas mas, sim, de imensuráveis sofrimentos e vexações.

"Remarque transformou sua vivência traumática em grito de alerta contra a romantização da guerra. Por assim dizer, ele funda uma nova tradição, a tradição do pacifismo..." como afirma, muito acertadamente, Elcio Cornelsen (2010, p. 53) em seu artigo.

\section{REINHARD GÖRING: SEESCHLACHT}

Trata-se de um drama do autor expressionista alemão Reinhard Göring (1887-1936), que terminou seus estudos em 1914, em Bonn, e foi enviado como médico militar ao Sarre, onde pegou tuberculose, doença que estava tratando até o final da guerra em Davos, na Suíça. Ao fim da Primeira Guerra Mundial, obteve seu doutorado em Medicina e publicou várias poesias na revista Der Sturm ("A tormenta”) e recebeu o prêmio Kleist em 1930. Afiliou-se ao Partido Comunista da Alemanha (KPD) e depois, por um breve período, ao Partido Nacional Socialista dos Trabalhadores Alemães (NSDAP). Suicidou-se em outubro de 1936, perto de Jena, depois de ter queimado seus manuscritos.

A peça Seeschlacht (Batalha naval), de Göring, foi escrita sob a impressão da Batalha da Jutlândia (31 de maio a 01 de junho de 1916) e descreve o destino de sete marinheiros que lutam dentro de uma torre de artilharia de um navio de guerra e morrem durante a batalha. A peça estreia, ainda durante a guerra, em 10 de fevereiro de 1917 e, um mês depois, foi encenada pelo famoso dramaturgo Max Reinhardt, em Berlim. Foi considerada, naquela época, como um grande escândalo e recebida com muita polêmica devido às suas tendências antiguerra e pacifistas, sendo desqualificada como uma obra defetista. Ao mesmo tempo, a obra é considerada uma peça que atingiu o auge do drama expressionista. O desumano da matança e de ser morto constitui um aspecto fundamental do drama, já que os homens são equiparados a porcos, bezerros e cães, como é possível ler em várias ocasiões:

"Pátria, pátria, amada pátria

Somos porcos 
Que esperam pelo açougueiro

Somos bezerros que são degolados

Nosso sangue colora os peixes!

Pátria, olha, olha, olha!

Porcos que são abatidos,

Bezerros que são degolados

Um rebanho destroçado pelo relâmpago

O golpe, o golpe, quando nos vai alcançar?

Pátria, pátria!

Que pretende ainda fazer conosco?"2

Contudo, existe também uma opinião contrária, que atribui à peça uma ruptura com o nacionalismo e o militarismo, pelo fato de proceder ao reconhecimento de uma necessidade trágica de guerra e vítimas (KREUZER, 1971, p. 90). Consequentemente, Göring é um dos poucos expressionistas que, supostamente, encontrou uma relação objetiva com aquela época e também com a guerra.

Como indício para isso, relembre-se o comportamento do quinto marinheiro, que atirou bem, embora, na realidade, queria se sublevar:

"A batalha continua, está ouvindo?

Não feche os seus olhos ainda

Atirei bem, não é?

Também teria me rebelado bem! Como?

Porém atirar era mais fácil para nós? Como?

Deve ter sido mais fácil ao nosso alcance?"3

Nessa passagem, nota-se uma frase no futuro do pretérito que articula uma teoria e, simultaneamente, utiliza o conceito do destino como álibi. Pode-se observar uma certa ambivalência nas palavras do quinto marinheiro, que luta com os outros, acerta algo ou alguém e também é atingido. Da mesma forma que os outros, ele está condenado a morrer e continua lutando apesar da sua tendência à rebelião até o fim desastroso. A peça, cujo autor foi criticado várias vezes, por ter posições nacionalistas precisamente por esta cena, termina com a saída de tal personagem.

Ademais, há uma terceira forma de recepção, alheia a qualquer tendência a favor ou contra a guerra, que classifica a obra diretamente como metafísica. Assim ela foi recebida na sua estreia em Berlim, na qual não houve aplausos, mas um silêncio total de tanta verdadeira emoção (KREUZER, 1971, p. 90-91).

Nos tempos mais recentes, a crítica literária tem feito referências às metáforas de animais como leitmotiv, à presença das imagens expressivas no texto, assim como ao estilo da linguagem de Göring. O homem é considerado um ser manipulável, determinado por

2 Tradução nossa. Esta citação, como todas as outras, procede da edição de Seeschlacht na Internet na biblioteca Gutenberg: $<$ http://gutenberg.spiegel.de/buch/seeschlacht-612/1>.

3 Tradução nossa. <http://gutenberg.spiegel.de/buch/seeschlacht-612/1>. 
outros, não sendo sujeito, senão objeto do seu destino, e que, desta forma, acaba por abandonar sua autodeterminação. Assim ocorre uma tragédia, pela qual a própria humanidade, aqui representada pelos soldados da marinha, é responsável, como articula também o primeiro marinheiro: “A culpa é nossa!”. Lillyman (apud KREUZER, 1971, p. 91) chama este comportamento dos marinheiros de Failure of the will ("fracasso da vontade", tradução nossa). No final da batalha naval está a derrota completa e a morte sem sentido, o que se expressa nas diferentes vozes, quando o primeiro, o quarto e o quinto marinheiro agonizam ao mesmo tempo.

O destino dos soldados da marinha na torre de artilharia se transforma num símbolo de uma situação existencial de estar encerrado (KREUZER, 1971, p. 95), uma vez que os marinheiros ficaram isolados de todas as referências sociais e saídas possíveis. Sofreram tal destino 156 soldados do cruzador de batalha SMS Derfflinger, que foram carbonizados nas torres $\mathrm{C}$ e D da popa do navio e somente um homem, de ambas as tripulações das torres, conseguiu salvar-se. Apesar dessa tragédia e da entrada de 3.000 toneladas de água, o navio continuava atacando os navios de guerra mais avançados do inimigo inglês, segundo a ordem do vice-almirante Scheer, que exigia o máximo desempenho dos cruzadores de batalha no ataque.

\section{O ENCONTRO DE VICENTE BLASCO IBÁÑEZ COM A PRIMEIRA GUERRA MUNDIAL}

Vicente Blasco Ibáñez estava arruinado e desiludido no caminho de volta à Argentina, a bordo do navio alemão de passageiros Friedrich August Rei, quando ouviu, pela primeira vez, sobre a probabilidade de um conflito iminente na Europa, após os passageiros alemães falarem de uma guerra preventiva. O navio alemão não pôde atracar em Le Havre, porém os passageiros conseguiram desembarcar no mar. A corrida armamentista entre a Grã-Bretanha e a Alemanha, bem como a crise marroquina e as guerras nos Bálcãs, em 1912 e 1913, haviam agravado as tensões, de modo que uma centelha, na forma do assassinato do Arquiduque Franz Ferdinand de Habsburgo, em 28 de junho de 1914, fez explodir a situação.

O autor valenciano decide ficar em Paris e acompanhar o conflito de perto. Ele toma partido da França em suas reportagens de jornal, romances e contos. Engaja-se pelo país anfitrião e, numa viagem para sua terra natal, Valência, informa sobre as origens do conflito, num momento em que a Espanha parece estar dividida entre seguidores germanófilos, de um lado, e francófilos e aliados, do outro lado. Trata-se de uma guerra de palavras e discussões nos cafés, que dividia os intelectuais da Espanha em dois bandos inconciliáveis. Já nos primeiros meses da guerra, não houve nenhum escritor que pudesse se esquivar deste desenvolvimento e que não tomasse posição.

\subsection{A guerra europeia na obra de Vicente Blasco Ibáñez}

As crônicas e reportagens e, sobretudo, a História de la Guerra Europea de 1914, em seus nove volumes, serão a ocupação principal do autor durante a guerra. Essa história da 
Primeira Guerra Mundial foi ilustrada com milhares de fotografias, desenhos e imagens. No início de sua introdução, Blasco Ibáñez sublinha a singularidade deste evento, quando escreve:

\footnotetext{
"No hay en la historia de la humanidad guerra alguna que pueda compararse con la presente. Las grandes invasiones de los bárbaros que dieron fin a la llamada Edad Antigua; las avalanchas galopantes de los hunos y de las hordas mongólicas; los choques europeos que por su duración recibieron los títulos de Guerra de Cien Años y Guerra de Treinta Años; los avances arrolladores del turco hasta los muros de Viena; las campañas de los reyes españoles contra medio mundo; las conquistas napoleónicas que durante quince años trajeron trastornado al continente; todos los hechos de la historia belicosa de los hombres, palidecen y se achican frente a la guerra de 1914." (BLASCO IBAÑEZ, 1914, p. 9).
}

Entretanto, também a sua obra narrativa servia de apoio à tarefa de defender a posição da França, com os mesmos objetivos políticos. Tanto os três romances como os oito contos são publicados a partir de 1916, quando o conflito já dura dois anos. O primeiro romance deste ciclo, Los cuatro jinetes del Apocalipsis, foi publicado em março de 1916; Mare nostrum, em janeiro de 1918 e Los enemigos de la mujer em 1919, quando a guerra já havia terminado há vários meses.

\subsection{Los cuatro jinetes del Apocalipsis}

Este romance de Vicente Blasco Ibáñez se transformou num bestseller, também na sua tradução inglesa. No ano de 1921, o The Illustrated London News considerava o livro como o mais lido depois da Bíblia e fez de Blasco Ibáñez não somente um autor de fama mundial, mas também um homem rico. Pelos direitos para a primeira versão cinematográfica, em 1921, recebeu 200.000 dólares, enquanto os direitos de tradução para o inglês só renderam 300 dólares. Até setembro de 1924 foram impressos 148.000 exemplares somente na Espanha, e, na América Latina, houve várias edições sem licença do autor.

Trata-se de um romance, obviamente a favor da República Francesa, e contra a ideologia do militarismo prussiano. Nele, a barbárie, a besta e o império do anticristo são identificados como o Império Alemão.

A obra é de construção linear, dividida em três partes. Na primeira, apresentam-se as bases do tema a ser desenvolvido, as causas da guerra e as negociações na sua véspera. $\mathrm{Na}$ segunda, é detalhado o transcurso das batalhas com os seus elementos ideológicos, históricos e narrativos. E, na terceira, chega-se ao clímax da narrativa, no qual todas as personagens sofrem na própria pele as consequências da guerra que ainda perdura.

Blasco Ibáñez obedece, de fato, à organização do texto bíblico e à abertura dos sete selos: o primeiro selo contém o Cavaleiro do Cavalo Branco, que simboliza a vitória e o poder; o segundo é o Cavaleiro do Cavalo Vermelho, que representa a guerra; o terceiro traz o Cavaleiro do Cavalo Preto, que representa a fome e, finalmente, surge o quarto cavaleiro, 
com uma armadura pálida que simboliza a morte, estando atrás dele o abismo. Dos outros três selos, Blasco Ibáñez somente usa o quinto, no qual as vítimas se reúnem para reclamar por justiça e reparação.

Quando Desnoyers, um dos protagonistas, é convidado para visitar o front, onde luta o seu filho, conversa com o russo Tchernoff e, no seu entusiasmo, acredita que a ofensiva do exercito francês poderia ser o início do fim da guerra. O russo, entretanto, declara-se bem mais pessimista, quando manifesta o seguinte:

"No; la Bestia no muere. Es la eterna compañera de los hombres, Se oculta chorreando sangre cuarenta años... sesenta años...un siglo, pero reaparece. Todo lo que podemos desear es que su herida sea larga, que se esconda por mucho tiempo y no la vean nunca las generaciones que guardarán todavía nuestro recuerdo." (BLASCO IBÁÑEZ, 2008, p. 396)

As descrições da guerra e de seus resultados possuem elementos do grotesco e do irônico, suscitando no leitor, através de sua crueldade, sentimentos de arrepio e aversão, que fazem identificar o conflito como algo anti-heroico e repugnante. Um exemplo disso pode ser verificado no momento em que os franceses conseguiram reconquistar as posições, no castelo de Desnoyers:

"Uno de estos jinetes se detuvo junto a la entrada del parque. El caballo devoró con avidez unos hierbajos, mientras el hombre permanecía encogido en la silla, como si durmiese. Desnoyers le tocó en una cadera, quiso despertarlo, e inmediatamente rodó por el lado opuesto. Estaba muerto; las entrañas colgaban fuera de su abdomen.Así había avanzado sobre su corcel, trotando confundido con los demás." (BLASCO IBÁÑEZ, 2008, p. 359-360)

Também em outro momento, quando os alemães são atacados no castelo pelos franceses, a guerra aparece como tempestade devastadora, numa descrição da cena de batalha completamente surreal, contendo detalhes cinematográficos e chocantes:

"Estaba llenando por tercera vez los cubos y contemplaba de espaldas al teniente, cuando ocurrió una cosa inverosímil, absurda, algo que le hizo recordar las fantásticas mutaciones del cinematógrafo. Desapareció de pronto la cabeza del oficial; dos surtidores de sangre saltaron de su cuello y el cuerpo se desplomó como un saco vacío. Al mismo tiempo un ciclón pasaba a lo largo de la pared, entre esta y el edificio, derribando árboles, volcando cañones, llevándose las personas en remolino como si fuesen hojas secas." (BLASCO IBÁÑEZ, 2008, p. 356-57). ${ }^{4}$

4 Esses acontecimentos, relatados pelo autor espanhol, não são autênticos. O navio alemão König Friedrich August ingressou nos estaleiros de Hamburgo, em abril de 1914, e lá permaneceu até o final da guerra. Portanto, não poderia ter realizado uma viagem da Argentina até a França em julho de 1914. 
Blasco Ibáñez não participa diretamente das ações bélicas, ele somente as observa, e as façanhas da guerra não são relatadas por uma testemunha, mas através de terceiros. As cenas de batalha são raras e as personagens principais não participam delas, já que são protagonizadas por soldados desconhecidos e sem nomes nos uniformes. O que interessa ao autor, mais que as ações de combate, são os acontecimentos atrás do front, naquela etapa, caracterizados acertadamente, assim como o comportamento das personagens e a atmosfera diante da ameaça iminente da guerra. Para tal finalidade, escolheu-se a família argentina Desnoyers, que vive na França e cujo destino é narrado no primeiro capítulo.

\section{CONCLUSÃO}

Os três textos apresentados aqui fornecem um pequeno recorte do impacto que a Primeira Guerra Mundial teve sobre a literatura de guerra. Eles podem ser classificados como literatura antiguerra, que mostra o lado abjeto, feio, cruel e repugnante do confronto bélico, sendo o texto de destaque o de Erich Maria Remarque, que entrou no cânone da literatura mundial transformando-se num bestseller eterno. Observa-se, em alguns momentos, que as técnicas do romancista alemão em retratar o impacto da guerra sobre o homem, nas suas facetas mais abomináveis, não são totalmente originais ou inovadoras, já que nas duas obras escritas durante a guerra, e analisadas aqui, foram encontrados elementos bastante parecidos, como o animalesco no comportamento dos soldados ou o jorro de sangue gorgolejante do soldado quando perde a cabeça.

Os outros dois textos caíram no esquecimento, evidenciando que existe uma literatura que não é atemporal e perde a sua atualidade e a sua expressividade com o tempo. O interesse pela literatura da Primeira Guerra Mundial diminui com os acontecimentos da Guerra Civil Espanhola, da Segunda Guerra Mundial e da Guerra do Vietnã, que tiveram uma grande repercussão, tanto na mídia quanto na literatura. Contudo, esta Grande Guerra Europeia permanece na memória como aquela que transformou a Europa e a literatura profundamente em todos os sentidos.

\section{BIBLIOGRAFIA}

Blasco Ibáñez, V. : Historia de la guerra europea de 1914: ilustrada com millares de dibujos, fotografias y laminas. Vol.1. Valencia: Prometeo, 1914. Disponível em: https://ia801406.us.archive. org/10/items/historiadelaguer01blas/historiadelaguer01blas.pdf, acesso em 15/06/2016.

BLASCO IBÁÑEZ, V. Los cuatro jinetes del Apocalipsis. Madrid: Alianza Editorial, 2008.

CORNELSEN, E. Cenas literárias da Primeira Guerra Mundial: Ernst Jünger e Erich Maria Remarque. In: CORNELSEN, E.; BURNS, T. (org.), Literatura e guerra. Belo Horizonte: Editora da UFMG, 2010. p. 29-54. 
GÖRING, R. Seeschlacht. Berlim: S. Fischer Verlag, 1918. Disponível em: <http://gutenberg.spiegel.de/ buch/seeschlacht-612/1>. Acesso em 28 de fev. 2016.

KREUZER, H. Fatalistischer Heroismus, “Willkommener Tod” Reinhard Goering Miszellen (mit Nachlasszitaten). Rice University Studies, 57, 4, p. 89-110, 1971.

REMARQUE, E. M. Nada de novo no front. Rio de Janeiro: Editora Abril, 1974. 